\title{
Forest Range Strong Room Robbery Case: Examination of Lock and Gas Cutter Tool Marks - A Case Study
}

\section{P. N. Ramakrishnan}

Junior Scientific Officer, H.O.D (Physics) Central Forensic Science Laboratory, Hyderabad, India

\begin{abstract}
In crime cases of robberies and thefts it is very important to ascertain the nature of weapon / tools involved and also the position of the locks. These details provide many vital clues regarding the modus operandi of the crime which helps the investigating agencies in solving the case. Examination of position of the lock and levers inside the lock aid in throwing light on how the crime was committed. In the present case study, the forensic examination of the breaking open of the lock of the strong room using gas cutter and arrival of conclusion based on the tool marks are discussed.
\end{abstract}

Keywords: Lock position; Gas cutter tool marks; Forensic characteristics

\section{Introduction}

A case of theft was received wherein, the strong room of the Forest Range office was broken and sandal wood oil and ivory worth lakhs of rupees was stolen. As per details given by the forwarding authority, the strong room is fitted with a steel door in steel frame embedded to the wall. The door is bolted using a steering wheel (Figure 3) fixed on the door. Then the lock is locked to prevent the movement of the steering wheel. The lever assembly connected to the steering wheel is fitted on the back side of the steel door and it is covered by steel sheet. The steel door opens towards outside and inside it a lock is fitted to the strong room. The Lock is operated using four keys in a sequential order where two keys operate the lever on the top side and other two keys operate the lever in the lower portion respectively.

When the investigating team arrived at the scene of crime, it was found that the bottom left corner of the strong room was cut diagonally

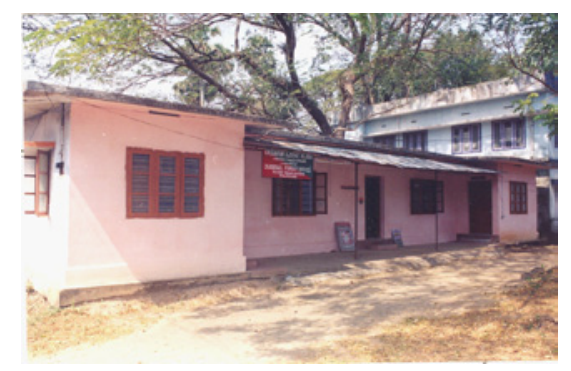

Figure 1: The outside view of the Forest Range office building.

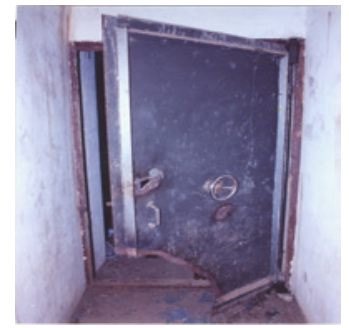

Figure 2: The damaged strong room.

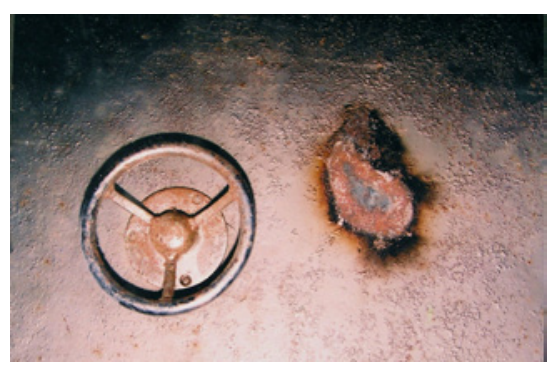

Figure 3: Strong room door with the steering wheel.

and separated. When the keys were inserted in key hole they could not be turned and also the steering wheel of the strong room could not be rotated. The investigating officers forwarded the laboratory, the cut portion of the strong room close to the door, the lock and keys, metal sheets with wielding marks on it and a metal sheet with sample gas cutting marks.

The following queries were asked for examination:

1. Whether the lock in the present condition be opened using the four set of keys?

2. Whether the lock was in locked position or in unlocked position when the lock was gas cut?

3. Whether the cut marks / tool marks on the lock and doors of the strong room were formed using gas cutter?

4. Whether any sign of external force is present on the lock apart from the gas cutter marks?

5. Whether the steel doors of the strong room were gas cut from inside or outside?

${ }^{*}$ Corresponding author: P. N. Ramakrishnan, Junior Scientific Officer, H.O.D (Physics) Central Forensic Science Laboratory, Hyderabad, India, E-mail: pnrkrishna@rediffmail.com

Received March 04, 2011; Accepted March 23, 2011; Published March 29, 2011

Citation: Ramakrishnan PN (2011) Forest Range Strong Room Robbery Case: Examination of Lock and Gas Cutter Tool Marks - A Case Study. J Forensic Res 2:120. doi:10.4172/2157-7145.1000120

Copyright: (c) 2011 Ramakrishnan PN . This is an open-access article distributed under the terms of the Creative Commons Attribution License, which permits unrestricted use, distribution, and reproduction in any medium, provided the original author and source are credited. 
Citation: Ramakrishnan PN (2011) Forest Range Strong Room Robbery Case: Examination of Lock and Gas Cutter Tool Marks - A Case Study. J Forensic Res 2:120. doi:10.4172/2157-7145.1000120

\section{Materials and Methods}

For query no. 1 the keys were inserted into the key hole of the lock (Figure 7,8 ) and operated. It was found that the keys could not be turned as a portion of the lock is damaged due to gas cutting (Figure 4, 5). Also the keys were observed microscopically, no usage marks were found on the key.

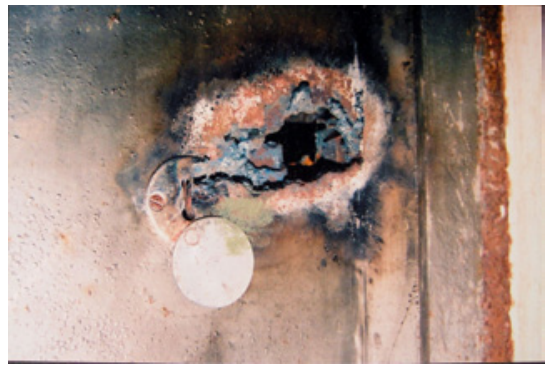

Figure 4: Strong room door with the steering wheel.

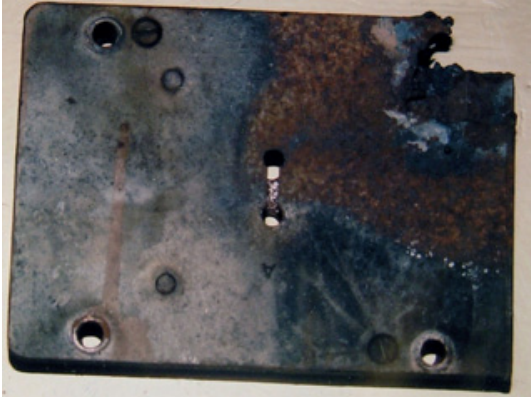

Figure 5: Strong room lock with levers inside.

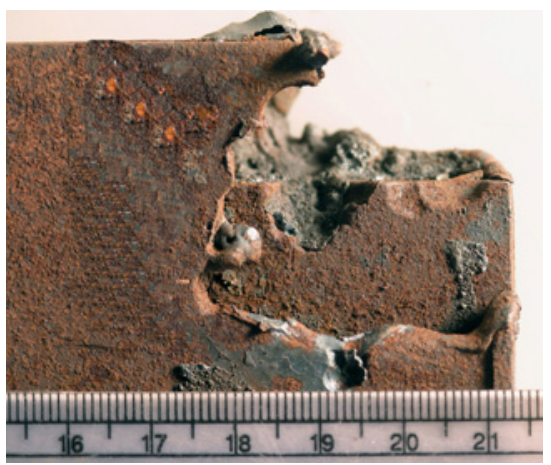

Figure 6: Part of the lock damaged

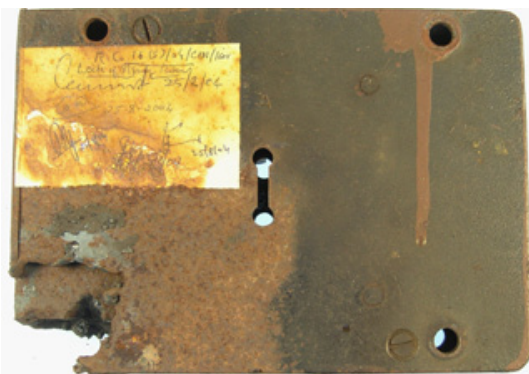

Figure 7: Strong room lock.

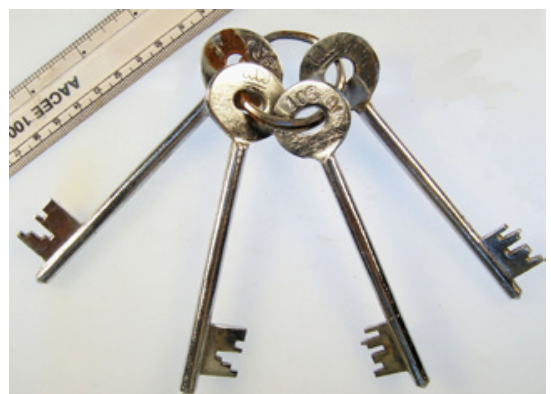

Figure 8: Strong room keys.

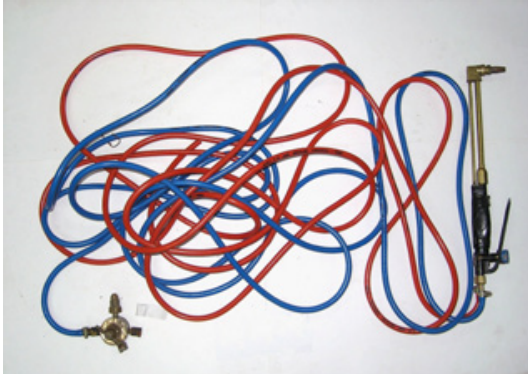

Figure 9: Seized gas cutter.

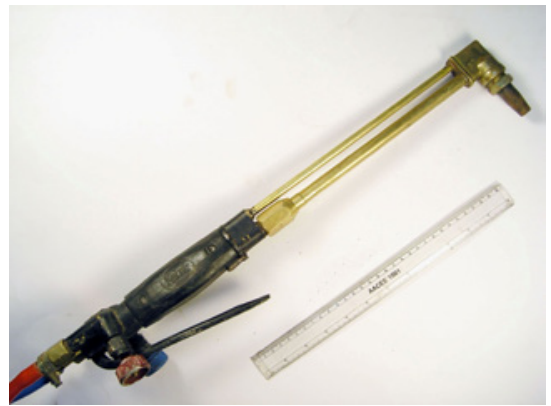

Figure 10: The nozzle of the gas cutter.

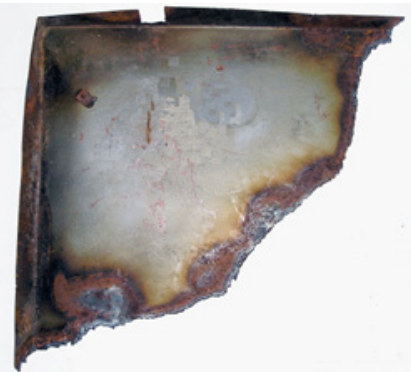

Figure 11: One of the pieces of the strong room door.

For query no.2 the continuity of the melting metal was observed on the lock (Figure 5, 6). The melting metal of the lock showed continuity and no dislocation of metal or melted metal was observed and the top lever was drawn inside. Hence it can be inferred that the lock was in unlock condition.

For query no. 3 the gas cut marks found on the strong room doors and the control gas cut marks (Figure 13, 14, 15) forwarded were 
Citation: Ramakrishnan PN (2011) Forest Range Strong Room Robbery Case: Examination of Lock and Gas Cutter Tool Marks - A Case Study. J Forensic Res 2:120. doi:10.4172/2157-7145.1000120

observed visually and microscopically $[1,2]$. The characteristic features of the tool marks and the beading formed due to melting of the metal found on both were compared.

For query no.4 the lock was observed under stereo-microscope $[1,3]$ in normal and oblique lighting and no characteristic features of external force or impact other than the gas cut marks found.

For query no.5 the direction of the beads (Figure 15, 16) formed inside or outside the metal door was observed. When a gas cutter is used the due to the heat produced the metal melts and when cooled forms of bead in the direction opposite to that from where it is cut.

\section{Results and Discussion}

The examination of the lock and keys showed that the keys cannot be operated into the lock in the present condition. The position of the levers in the lock suggests that the lock was in unlocking position. Based on the microscopic and visual comparison of the tool marks[1,2] formed on the strong room doors and the control gas cut marks, it could

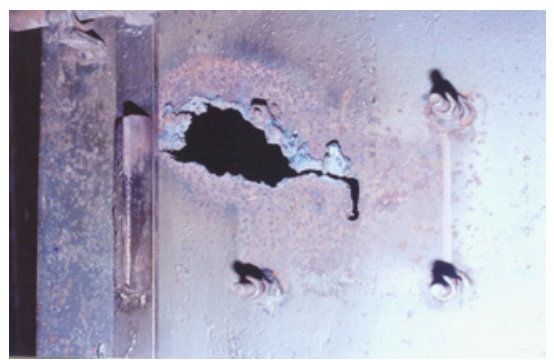

Figure 12: Gas cut marks on the strong room door.

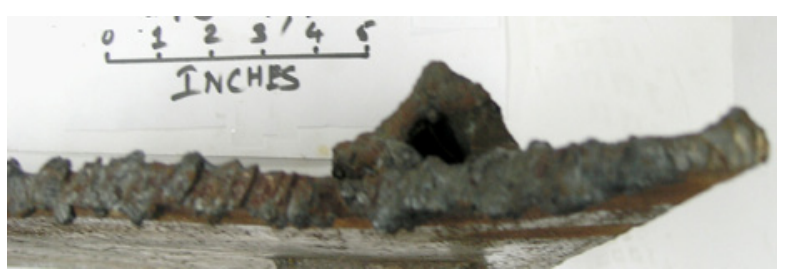

Figure 13: The gas cut tool marks on the piece of the strong room door.

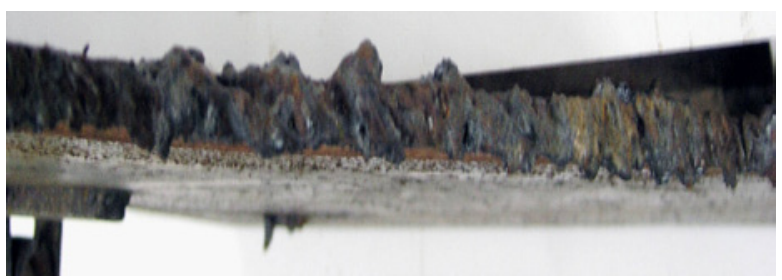

Figure 14: The gas cut tool marks on the piece of the strong room door.

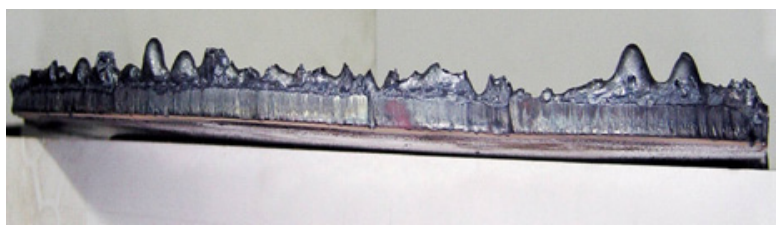

Figure 15: The beading formation

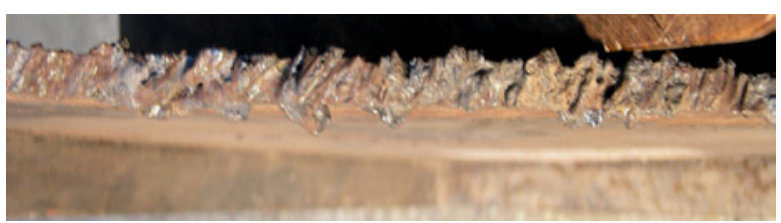

Figure 16: The control gas cut tool marks as sent by forwarding authority.

be opined that the strong room was cut using a gas cutter. No external force other than the gas cut marks were found on the lock. Also it could be opined whether the cut was made from inside or outside clearly from the beading formation on the sheets.

\section{Conclusion}

The examinations and observations made by physical and microscopic methods could give the vital clues to the investigating team that the lock was in unlocked position when the offence was committed and the cut marks on the strong room was found to be that of the gas cutter but the exact nature of gas cutter used could not be ascertained. The study can be further extended in analyzing the various types of gas cutters using different types of gases like LPG, Oxyacetylene, etc by making tool marks using all available varieties of gas cutter like electrical arc and plasma cutters.

\section{References}

1. Richard Saferstein (1982) Forensic Science Handbook, Prentice Hal Publications, Eaglewoods cliffs, New Jersey, USA.

2. Paul L Kirk (1966) Crime Investigation Physical Evidence and Police laboratory, Inter Science Publishers, New York, USA.

3. Peter McDonald The Tire Imprint Evidence Elsevier Science Publishing Co., Inc. New York, USA. 